\title{
Hepatic dysfunction in critically ill patients
}

\author{
Jeong Hoon Yang \\ Division of Cardiology, Department of Critical Care Medicine and Medicine, Samsung Medical Center, Sungkyunkwan University School of Medicine, Seoul, \\ Korea
}

Abnormal liver chemistry tests indicating hepatic dysfunction are a common finding in critically ill patients [1]. Hepatobiliary enzyme levels interpreted in isolation convey information on the level of ongoing injury; bilirubin, albumin, and international normalized ratio convey information on liver function; and platelets convey information on severity of fibrosis [2]. Hepatic dysfunction must be interpreted in the clinical context of a given patient because the numerous liver biomarkers indicate different pathways of hepatic dysfunction and can be influenced by extrahepatic factors such as age, diet, or pregnancy [3]. Particularly, hepatic dysfunction is closely related to clinical outcome in the critically ill and is included in most of the widely used clinical risk scoring systems in the setting of intensive care unit such as Acute Physiology and Chronic Health Evaluation II (APACHE II; cirrhosis as a factor), Sequential Organ Failure Assessment (SOFA; bilirubin as components), or Simplified Acute Physiology Score (SAPS; bilirubin as components) [4]. Hypoalbuminemia, which is a component variable in APACHE III, was also related to clinical outcome in acute ill patients and its association may reflect nutritional status and inflammation [5]. Accordingly, we suspect that the prognostic power of bilirubin/albumin ratio would be better than that of bilirubin or albumin alone.

This study showed the receiver operating characteristic curves of bilirubin, bilirubin to albumin ratio, and APACHE II score, with respective area under the curve of 0.599, 0.628 and 0.666 for mortality of critically ill patients admitted to a medical intensive care unit [6]. The receiver operating characteristic curves between bilirubin to albumin ratio and APACHE II score were not significantly different $(\mathrm{P}=0.282)$. Furthermore, our group investigated the association between hepatic dysfunction and clinical outcomes in 365 patients who underwent extracorporeal cardiopulmonary resuscitation (unpublished data). Hyperbilirubinemia was a significant predictor for in-hospital mortality on multivariable analysis.

Taken together, pre-existing data indicate that hepatic dysfunction is a common in various medical conditions and is associated with mortality. Therefore, physicians should carefully monitor the development of hepatic dysfunction with several biomarkers in critically ill patients.

\section{CONFLICT OF INTEREST}

No potential conflict of interest relevant to this article was reported.

\section{Editorial}

Received: February 25, 2020

Accepted: February 26, 2020

Corresponding author Jeong Hoon Yang Division of Cardiology, Department of Critical Care Medicine and Medicine, Samsung Medical Center, Sungkyunkwan University School of Medicine, 81 Irwon-ro, Gangnamgu, Seoul 06351, Korea Tel: +82-2-3410-1768 Fax: +82-2-2148-7088 E-mail: jhysmc@gmail.com

Copyright (๑) 2020 The Korean Society of Critical Care Medicine

This is an Open Access article distributed under the terms of Creative Attributions Non-Commercial License (https:// creativecommons.org/li-censes/by-nc/4.0] which permits unrestricted noncommercial use, distribution, and reproduction in any medium, provided the original work is properly cited. 


\section{ORCID}

Jeong Hoon Yang https://orcid.org/0000-0001-8138-1367

\section{REFERENCES}

1. Fuhrmann V, Kneidinger N, Herkner H, Heinz G, Nikfardjam M, Bojic A, et al. Hypoxic hepatitis: underlying conditions and risk factors for mortality in critically ill patients. Intensive Care Med 2009;35:1397-405.

2. Newsome PN, Cramb R, Davison SM, Dillon JF, Foulerton M, Godfrey EM, et al. Guidelines on the management of abnormal liver blood tests. Gut 2018;67:6-19.

3. Kwo PY, Cohen SM, Lim JK. ACG clinical guideline: evalua- tion of abnormal liver chemistries. Am J Gastroenterol 2017; 112:18-35.

4. Koch A, Horn A, Dückers H, Yagmur E, Sanson E, Bruensing J, et al. Increased liver stiffness denotes hepatic dysfunction and mortality risk in critically ill non-cirrhotic patients at a medical ICU. Crit Care 2011;15:R266.

5. Knaus WA, Wagner DP, Draper EA, Zimmerman JE, Bergner M, Bastos PG, et al. The APACHE III prognostic system: risk prediction of hospital mortality for critically ill hospitalized adults. Chest 1991;100:1619-36.

6. Choi JS, Chung KS, Lee EH, Lee SH, Lee SH, Kim SY, et al. The role of bilirubin to albumin ratio as a predictor for mortality in critically ill patients without existing liver or biliary tract disease. Acute Crit Care 2020;35:24-30. 